Check for updates

Montreal

Cite this as: $B M J 2021 ; 373: n 888$ http://dx.doi.org/10.1136/bmj.n888 Published: 01 April 2021

\title{
Covid-19: Moderna and Pfizer vaccines prevent infections as well as symptoms, CDC study finds
}

\section{Owen Dyer}

Vaccination with the Pfizer or Moderna vaccine reduces infections by $90 \%$, while a single dose confers $80 \%$ protection, shows a study led by the US Centers for Disease Control and Prevention (CDC) that followed essential workers through the worst months of the pandemic.

The study is one of a small number that employ regular testing to measure vaccines' impact on infection rates rather than counting cases of symptomatic disease, hospital admission, or death.

The participants were 3950 essential workers, with no documented history of SARS-CoV-2 infection, in eight largely urban US locations. Of these people, $2479(63 \%)$ received both vaccine doses, 477 (12\%) received only one dose, and 994 (25\%) were unvaccinated.

The study opened on the same day as the US vaccination programme, 14 December 2020, and most of the people vaccinated received their first shot within two weeks. The first week of January 2021 saw the highest rate of daily new infections yet seen in the US, about 250 ooo a day. Researchers stopped collecting data on 13 March.

Participants were taught to swab themselves once a week and also when they felt any symptoms, shipping the swabs on cold packs for laboratory polymerase chain reaction assay. Most infections (58\%) were detected by weekly testing, but $87 \%$ of detected infections did ultimately produce covid-19 symptoms.

Of 172 infections detected, 161 occurred in the unvaccinated arm of the trial, which saw a rate of 1.38 infections per 1000 person days. Among participants who had received only one shot at least 14 days previously, the rate was 0.19 infections per 1000 person days. Among those who had received a second shot at least 14 days previously, it was 0.04 per 1000 person days.

This translated to an adjusted vaccine effectiveness of 90\% with full immunisation (95\% confidence interval $68 \%$ to $97 \%$ ) and of $80 \%$ with partial immunisation (59\% to 90\%). Adjustment for age, sex, race, or study location barely changed these results.

The study was not adequately powered to differentiate between Moderna's vaccine and Pfizer's, which accounted for two thirds of the doses given.

\section{Categories of workers}

The majority of participants were white, female, and aged 18-49, making this a younger study population than in the phase III clinical trials of these two vaccines.

Infection rates were largely unaffected by race, age, or sex, but they varied sharply among different categories of workers, primarily owing to different rates of vaccine uptake. Vaccination rates among doctors were $92 \%$, nurses $82 \%$, and first responders $64 \%$, and the infection rates in these categories were 1.9\% (doctors), $5.0 \%$ (nurses), and 8.8\% (first responders).

The results are in line with those seen in two other recent studies of the Pfizer vaccine's impact on infection rates, in the $\mathrm{UK}^{1}$ and Israel. ${ }^{2}$

The CDC study is reported in the agency's Morbidity and Mortality Weekly Report (MMWR). Whistleblowers at the CDC warned last year that this mainstay of US epidemiology was being pressured by Trump administration officials who sought to water down its reports on the pandemic and its advice on infection hazards. ${ }^{3}$

Robert Redfield, a Trump appointee who recently left his role as CDC director, told a CNN news special this week that the interference had come from the former health secretary Alex Azar. "[What] I was the most offended by was the calls that wanted me to pressure and change the $M M W R$," said Redfield. "He may deny that, but it's true." 4

Azar replied in a statement, “Any suggestion that I pressured or otherwise asked Dr Redfield to change the content of a single scientific, peer reviewed MMWR article is false.”

Hall VJ, Foulkes S, Saei A, et al. Effectiveness of BNT162b2 mRNA vaccine against infection and covid-19 vaccine coverage in healthcare workers in England, multicentre prospective cohort study (the SIREN Study). Lancet 2021 [preprint]. https://papers.ssrn.com/sol3/papers.cfm?abstract_id=3790399.

2 Thompson MG, Burgess JL, Naleway AL, et al. Interim estimates of vaccine effectiveness of BNT162b2 and mRNA-1273 covid-19 vaccines in preventing SARS-CoV-2 infection among health care personnel, first responders, and other essential and frontline workers-eight US locations, December 2020-March 2021. MMWR Morb Mortal Wkly Rep 2021 Mar 29. https://www.cdc.gov/mmwr/volumes/70/wr/mm7013e3.htm.

3 Dyer 0. Trump appointees tamper with renowned CDC publication, claiming that scientists are trying to "hurt the president". BMJ2020;370:m3589. doi: 10.1136/bmj.m3589 pmid: 32933896

4 Howard J. What the Covid-19 war was really like in Trump's White House CNN2021 Mar 28. https://edition.cnn.com/2021/03/28/health/covid-wardoctors-fauci-birx-hahn-redfield-gupta-bn/index.html.

This article is made freely available for use in accordance with BMJ's website terms and conditions for the duration of the covid-19 pandemic or until otherwise determined by BMJ. You may use, download and print the article for any lawful, non-commercial purpose (including text and data mining) provided that all copyright notices and trade marks are retained. 